\title{
Incidence of congenital uterine malformation in fertile female population undergoing laparoscopic tubal ligation at a tertiary care centre, Lucknow, Uttar Pradesh, India: a study of six years
}

\author{
Deepali Srivastava ${ }^{1}$, Sandeepa Srivastava ${ }^{2 *}$
}

\author{
${ }^{1}$ Department of Obstetrics and Gynecology, KGMU, Lucknow, Uttar Pradesh, India \\ ${ }^{2}$ Consultant Gynecologist, RMLIMS, Lucknow, Uttar Pradesh, India
}

Received: 26 January 2020

Revised: 19 February 2020

Accepted: 24 February 2020

\section{*Correspondence:}

Dr. Sandeepa Srivastava,

E-mail: sandeepashrivastava02@gmail.com

Copyright: (C) the author(s), publisher and licensee Medip Academy. This is an open-access article distributed under the terms of the Creative Commons Attribution Non-Commercial License, which permits unrestricted non-commercial use, distribution, and reproduction in any medium, provided the original work is properly cited.

\section{ABSTRACT}

Background: Congenital uterine anomalies are not only uncommon, many are asymptomatic. A uterine malformation is a type of female genital malformation resulting from an abnormal development of the mullerian ducts during embryogenesis. The prevalence of uterine malformation is estimated to be $6.7 \%$ in general population.

Methods: This study has included 2423 women who attended family planning OPD in KGMU for purpose of laparoscopic tubal ligation along with general and systemic examination. During the laproscopic ligation procedure the observed uterine anomalies were noted and compared to the data available in the existing medical literature.

Results: Out of 2423 females included in this study during 2011-2016, 104 (4.29\%) females were diagnosed with uterine anomalies. The Commonest uterine anomaly was arcuate uterus which was seen in 77 patients. (3.1\%). Unicornuate uterus was seen in 19 patients $(0.8 \%)$ and bi-cornuate uterus was seen in 9 patients $(0.3 \%) .3$ out of these were uni-cornuate uterus with rudimentary horn.

Conclusions: Though the congenital uterine malformations are frequent findings in infertile patients but few malformations like uni-cornuate uterus, arcuate uterus and bicornuate uterus are although rare but seen in fertile females, showing their lesser impact on pregnancy and its outcome.

Keywords: Congenital uterine malformations, Fertile female, Laparoscopic tubal ligation

\section{INTRODUCTION}

Congenital uterine anomalies are not only uncommon, many are asymptomatic. A uterine malformation is a type of female genital malformation resulting from an abnormal development of the mullerian ducts during embryogenesis. ${ }^{1}$ Symptoms range from amenorrhea and infertility, recurrent pregnancy loss and pain to normal functioning depending on the nature of the defect. ${ }^{1-6}$ The prevalence of uterine malformation is estimated to be $6.7 \%$ in general population, slightly higher $(7.3 \%)$ in the infertility patient and significantly higher in a population of woman with history of recurrent pregnancy loss $(16 \%)^{7-9}$

\section{Uterine development}

The uterus is formed at around 8-16 weeks of foetal life from the development of the two paired paramesonephric ducts, called mullerian ducts. ${ }^{10,11}$ The process involves three main stages:

- Organogenesis: The development of both mullerian ducts. 
- Fusion: The lower mullerian ducts fuse to form the upper vagina, cervix and uterus; this is termed lateral fusion. The upper cranial part of the mullerian ducts will remain unfused and form the fallopian tubes.

- Septal absorption: After the lower mullerian ducts fuse, a central septum is left which starts to resorb at approximately 9 weeks eventually leaving a single uterine cavity and cervix.

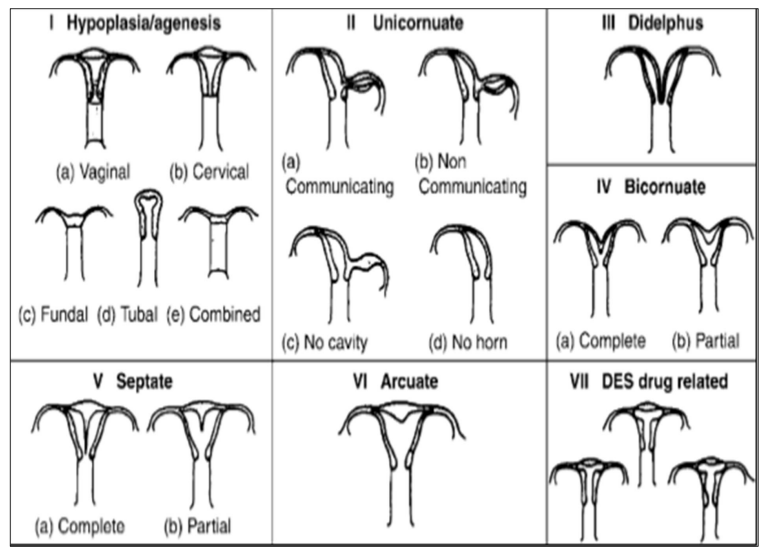

Figure 1: Uterine abnormalities as per the AFS (American Fertility Society - now American society of reproductive medicine).

\section{Classification of congenital uterine anomalies}

Congenital uterine anomalies may arise from malformations at any step of the mullerian developmental process. ${ }^{12}$ Buttram and Gibbons Saravelos et al, first proposed a classification of the congenital uterine anomalies based on the degree of failure of the mullerian ducts to develop normally, and divided them into groups with similar clinical manifestations, treatments and prognosis. ${ }^{13}$ This was revised and modified first in 1983 and then in 1988 by the American Society of Reproductive Medicine (formerly known as the American Fertility Society) to provide a classification which is now the most widely accepted and used worldwide. ${ }^{14}$ This consists of seven groups, some with further subdivisions (Devi Wold, 2006): ${ }^{12}$

\section{Mullerian agenesis or hypoplasia}

- Vaginal

- Cervical

- Fundal

- Tubal

- Combined.

Uni-cornuate uterus (agenesis or hypoplasia of one of the two mullerian ducts)

- With a communicating rudimentary horn

- With a non-communicating rudimentary horn

- With a rudimentary horn with no cavity
- With an absent rudimentary horn.

Didelphys uterus (failure of lateral fusion of the vagina and uterus mullerian ducts)

Bicornuate uterus (incomplete fusion of the uterine horns at the level of the fundus)

- Complete

- Partial.

Septate uterus (absent or incomplete resorption of the uterovaginal septum)

- Complete

- Partial.

Arcuate uterus (a mild indentation at the level of the fundus from a near complete resorption of the uterovaginal septum)

Diethylstilbestrol (DES) exposed uterus (T-shaped uterus resulting from DES exposure of the patient in utero)

The AFS (American Fertility Society - now American society of Reproductive medicine)

Classified uterine abnormalities as follows (Figure 1). ${ }^{14}$

- Class I - Mullerian agenesis (absent uterus)

- Class II - Uni-cornuate uterus (one sided uterus)

- Class III - Uterus didelphys (double uterus)

- Class IV - Bicornuate uterus (uterus with 2 horns)

- Class V - Septate uterus (uterine septum or partition)

- Class VI - DES uterus (T shaped uterine cavity).

Arcuate uterus - dimple at uterus fundus rudimentary horn with uni-cornuate uterus.

Present study is an observational study to evaluate the prevalence of these malformations in fertile females undergoing laparoscopic tubal ligations at our centre which went unnoticed during their pregnancy and child birth.

\section{METHODS}

This study has included 2423 women who attended family planning OPD in KGMU for purpose of laparoscopic tubal ligation along with general and systemic examination. $\mathrm{Hb}$ and urine for cells and sugar were done and all the protocols were followed according the checklist of GOI. And patients were selected accordingly. This study was done during the 6 years (January 2011 to December 2016). All the patients were operated under general anesthesia after taking proper written informed consent and a prior institutional ethical approval for the study. 
Eligibility criteria for laproscopic tubal ligation were as per family planning division ministry of health and family welfare, Government of India. Females of reproductive age group who were married, had at least one child over one year of age and were mentally and medically fit were included in this study after obtaining a written informed consent about the procedure.

During the laproscopic ligation procedure the observed uterine anomalies were noted and compared to the data available in the existing medical literature.

\section{Surgical technique}

Single puncture laproscopy was done under $\mathrm{I} / \mathrm{M}$ sedation and local anesthesia. After giving $10 \mathrm{ml}$ of $1 \%$ Xylocaine, an infra-umbilical transverse incision of 1-2 $\mathrm{cm}$ is given and then pneumo-peritonium was created by $\mathrm{CO} 2$ insufflations through Veress needles up to 11 to 13 mmHg. Then abdominal entry was made by trocor and canula. The obturator was directed towards pelvic cavity and then the laparoscope was introduced and peritoneal cavity was inspected. Simultaneously assistant is advised to elevate the uterus. Uterine contour, shape, round ligament, fallopian tube and ovary and ovarian ligament on both sides were inspected and findings were noted. Tubal ligation was done as per standard procedure. Abdomen was deflated, instruments were removed and abdomen portal stitched. Patient is watched for 4 hours post operatively and discharged in satisfactory condition.

\section{RESULTS}

Out of 2423 females included in this study during 20112016, 104 (4.29\%) females were diagnosed with uterine anomalies. Out of these patients, the commonest uterine anomaly was arcuate uterus which was seen in 77 patients $(77.1 \%)$. Uni-cornuate uterus was seen in 19 patients $(18.26 \%)$ and bi-cornuate uterus was seen in 9 patients $(8.6 \%)$. Out of these bi-cornuate uterus, 3 were uni-cornuate uterus with rudimentary horn.

\section{DISCUSSION}

The incidence of congenital uterine malformations are frequent findings in infertile patients but these malformations are also common findings in the fertile females having no or very little effect on pregnancy and its outcome. ${ }^{15-18}$ The prevalence of congenital uterine abnormalities has been reported in overall population between $1-10 \% .{ }^{19}$ Saravelos et al, estimated the presence of congenital uterine anomalies in recurrent miscarriages is high as $16.7 \%$ compared to $6.7 \%$ in general population based on a systemic review. ${ }^{17}$ In the present observational study certain long uterine anomalies has been found as frequently as $4.29 \%$ in fertile females. Commonest congenital uterine abnormality found was arcuate uterus (3.1\%); then uni-cornuate uterus $(0.8 \%)$ and bicornuate uterus $(0.3 \%)$. The above results are showing that though rare but certain mullerian abnormalities are not associated with poor pregnancy outcome or infertility and are not rare to find these uterine anomalies in fertile females.

\section{CONCLUSION}

Though the congenital uterine malformations are frequent findings in infertile patients but few malformations like uni-cornuate uterus, arcuate uterus and bicornuate uterus are although rare but seen in fertile females, showing their lesser impact on pregnancy and its outcome. So, this observational present study is showing that above mentioned abnormality is not associated with infertility with poor pregnancy outcome.

Funding: No funding sources

Conflict of interest: None declared

Ethical approval: The study was approved by the Institutional Ethics Committee

\section{REFERENCES}

1. Moore KL, Persaud TVN, Torchia MG. The urogenital system. Before we are born: essential of embryology and birth defects, $7^{\text {th }}$ Edn, Philadelphia: Saunders/ Elsevier; 2008:162-189.

2. Green LK, Harris RE. Uterine anomalies. Frequency of diagnosis and associated obstetric complications. Obstet Gynecol. 1976;47:427-9.

3. Rock JA, Murphy AA. Anatomic abnormalities. Clin Obstet Gynecol. 1986;29:886-911.

4. Acien P. Reproductive performance of women with uterine malformations. Hum Reprod. 1993;8:122-6.

5. Raga F, Bauset C, Remohi J, Bonilla-Musoles F, Simon C, Pellicer A. Reproductive impact of congenital mullerian anomalies. Hum Reprod. 1997; 12:2277-81.

6. Tomazevic T, Ban-Frangez H, Ribic-Pucelj M, Premru-Srsen T, Verdenik I. Small uterine septum is an important risk variable for preterm birth. Eur $\mathrm{J}$ Obstet Gynecol Reprod Biol. 2007;135:154-7.

7. Simon C, Martinez L, Pardo F, Tortajada M, Pellicer A. Mullerian defects in women with normal reproductive outcome. Fertil Steril. 1991;56:1192-3.

8. Saravelos SH, Cocksedge KA, Li TC. Prevalence and diagnosis of congenital uterine anomalies in women with reproductive failure: a critical appraisal. Hum Reprod Update. 2008;14:415-29.

9. Saravelos SH, Cocksedge KA, Li TC. The pattern of pregnancy loss in women with congenital uterine anomalies and recurrent miscarriage. Reprod Biomed Online. 2010;20:416-22.

10. Letterie GS. Structural abnormalities and reproductive failure: effective techniques of diagnosis and management. New York: Blackwell Science; 1998.

11. Braun P, Grau FV, Pons RM, Enguix DP. Is hysterosalpingography able to diagnose all uterine malformations correctly? A retrospective study. Eur J Radiol. 2005;53(2):274-9. 
12. Devi Wold AS, Pham N, Arici A. Anatomic factors in recurrent pregnancy loss. Seminars in Reprod Med. 2006;24(1):25-32.

13. Buttram VC, Gibbons WE. Mullerian anomalies: a proposed classification. Fertil Steril. 1979;32:40-6.

14. The American Fertility Society. The American Fertility Society classifications of adnexal adhesions, distal tubal occlusion, tubal occlusion secondary to tubal ligation, tubal pregnancies, Mullerian anomalies and intrauterine adhesions. Fertil Steril. 1988;49:944-55.

15. Nahum GG. Uterine anomalies. How common are they, and what is their distribution among subtypes? J Reprod Med. 1998;43:877-87.

16. Grimbizis GF, Camus M, Tarlatzis BC, Bontis JN, Devroey P. Clinical implications of uterine malformations and hysteroscopic treatment results. Hum Reprod Update. 2001;7:161-74.

17. Saravelos SH, Cocksedge KA, Li TC. The pattern of pregnancy loss in women with congenital uterine anomalies and recurrent miscarriage. Reprod Biomed Online. 2010;20:416-22.

18. Saovetrs SN, Cocksedge KA, Li T. Prevalence and diagnosis of congenital uterine anomalies in woman with reproductive failure: a critical appraisal. Human Reprod Update. 2008;14c5:415-29.

19. Chan YY, Jayaprakasan K, Tan A, Thornton JG, Coomarasamy A, Raine-Fennin NJ. Reproductive outcomes in women with congenital uterine anomalies: a systematic review. Ultrasound Obstet Gynecol. 2011;38:371-82.

Cite this article as: Srivastava D, Srivastava S. Incidence of congenital uterine malformation in fertile female population undergoing laparoscopic tubal ligation at a tertiary care centre, Lucknow, Uttar Pradesh, India: a study of six years. Int J Reprod Contracept Obstet Gynecol 2020;9:1398-401. 